\title{
Opinion piece: 2021 dreams of a hospitable society
}

\section{Paul Lynch}

\author{
Dr Paul Lynch is Honorary \\ Adjunct Professor at \\ Auckland University of \\ Technology, New Zealand. \\ His research focuses upon \\ critical and sociological \\ perspectives on hospitality \\ and the interactions between \\ host and guest, host and \\ home, the nature of \\ hospitality and how the study \\ of hospitality sheds light on \\ people, work, and society.
}

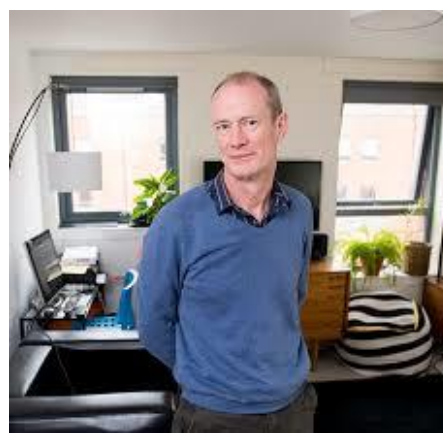

A benefit of the pandemic has been a pause in 'normality', allowing one to reflect: noticeable effects such as roads with near absence of cars, filled with pedestrians and cyclists who greet one another, a virtual absence of planes in the sky, a greater engagement of people with nature, with simple pleasures, a re-valuing of roles that have been deemed and rewarded commensurately as less valuable such as cleaners, refuse collectors, so-called front-line workers, etc. A return to the idea that 'we are all in it together', the idea that a society might be said to exist once more.

In 2021, the dominant neoliberal form of capitalism will end. As in New Zealand with a prioritisation of wellbeing over economic growth, no longer will governments focus budgets exclusively upon national gross domestic product and economic growth, reduction in public services, a fostering of individualism and private enterprise at the expense of community. The stain of having more food banks than McDonalds (UK perspective), $30 \%$ of children in poverty (UK), and don't get me started about the treatment of refugees and asylum seekers - it is beyond shame. The disenfranchising Anglo-Saxon version of democracy (the one I am most familiar with) will be replaced by a form of proportional representation where every vote has meaning, a fostering of strong consensus rather than partisan politics, whose endeavours will be for the benefit of society as a whole rather than at the behest of lobbying groups and 'generous donors'. In brief, politics will be governed by the creation of a hospitable society, where politicians and the media will not be permitted to foster and incite hate, discrimination and division with impunity, where eyeboggling wealth will no longer be concentrated in the hands of a tiny minority and where our largest organisations pay in relative terms the least amount of tax.

The implications for the hospitality industry are profound. Success of organisations will be based upon economic, environmental and hospitable employer footprints - the latter including inter alia payment of a hospitable living wage ${ }^{1}$, inclusivity and equality - and that such words have meaning and actions rather than conforming to the satisfaction of tick-box management measures. The loss of meaning and a smokescreen of rhetoric over substance through the relentless pursuit of efficiency and economic success over effectiveness (think McDonaldisation ++ ) undermines many an organisation and consumer experience. 
Climate change concerns will be at the forefront, challenging the consumer culture that has led to global ecological degradation, that means we each consume through our food and drink the equivalent of a plastic debit card per week, that we recognise that every single purchase has an ecological cost. None of this is rocket science. It simply needs a step back for reflection and a willingness to accept that society could be so much better, that in so many ways we have progressed backwards. Without doubt, 2021 has the potential to be the start of a truly transformational and inspirational year.

\section{Corresponding author}

Paul Lynch can be contacted at: karabiner 315@hotmail.com

\section{References}

(1) Douglas, J., Williamson, D., Harris, C. Dirty deeds done dirt cheap: Creating "hospitable wages" through the Living Wage Movement. Hospitality \& Society, 2020, 10 (1) 3-22. https://doi.org/10.1386/hosp_00010_1 